\title{
Comparison of Chemical and Enzymatic Interesterification of Fully Hydrogenated Soybean Oil and Walnut Oil to Produce a Fat Base with Adequate Nutritional and Physical Characteristics
}

\author{
Mariel Farfán, Alfredo Álvarez, Alan Gárate and Pedro Bouchon* \\ Pontificia Universidad Católica de Chile, Department of Chemical and Bioprocess Engineering, \\ Vicuña Mackenna 4860, 6904411 Santiago, Chile
}

Received: August 11, 2014

Accepted: March 23, 2015

\begin{abstract}
Summary
The optimal physical, chemical and nutritional properties of natural lipids depend on the structure and composition of triacylglycerols. However, they are not always mutually compatible. Lipid modification is a good way to give them specific functionalities, increase their oxidative stability, or improve their nutritional value. As such, chemical and enzymatic interesterification may be used to modify them and produce structured lipids. In accordance, the aim of this study is to compare chemical and enzymatic interesterification of binary blends of fully hydrogenated soybean oil and walnut oil, using sodium methoxide or Lipozyme TL IM, respectively, to produce a fat base with adequate nutritional and physical characteristics. Three different mass ratios of fully hydrogenated soybean oil and walnut oil blends (20:80, 40:60 and 60:40) were interesterified and evaluated. Total interesterification was determined by the stabilization of the solid fat content. Chemical reaction of the 20:80 blend was completed in $10 \mathrm{~min}$ and of the 40:60 and 60:40 blends in 15 min. Enzymatically interesterified blends were stabilized in $120 \mathrm{~min}$ at all of the mass ratios. Complete interesterification significantly reduced the solid fat content of the blends at any composition. Chemical and enzymatically interesterified fully hydrogenated blend of soybean and walnut oil at mass ratio of 40:60 showed the plastic curve of an all-purpose-type shortening rich in polyunsaturated fatty acids, with a high linolenic acid (C18:3n3) content and with zero trans-fatty acids.
\end{abstract}

Key words: chemical interesterification, enzymatic interesterification, triacylglycerol, hydrogenated soybean oil, walnut oil, solid fat content

\section{Introduction}

Lipids are the highest energy source of the three macronutrients (carbohydrates, proteins and lipids). They also add flavour, texture and satiety to foods. Slight differences in the fat produce significant changes in the food. For instance, a fat that performs well in baked products will not work well enough in ice cream, producing a pasty and waxy feeling instead of a pleasant cooling effect (1). On the other hand, some fats may have excellent physical properties for specific applications but are not recommended due to nutritional concerns. These lipids may not be absorbed as expected or may even have some deleterious effects on health due to the presence of certain fatty acids. Each of the three fatty acids bonded to the sn1 , sn-2 or sn-3 position of the glycerol backbone can vary in regard to chain length, number and position of double bonds, and geometrical configuration. These characteristics give lipids their physical, chemical and nutritional properties $(2,3)$. 
The optimal physical, chemical and nutritional properties of an oil or fat are not always mutually compatible (4). As such, lipid modification is a good way to give them specific functionalities, increase their oxidative stability, or improve their nutritional value. The temperature at which fats crystallize and melt or the ratio and kind of solid and liquid fats that produce a specific plastic behaviour are physical properties that are specific for each application (4). Concerns about trans configuration or actions to reverse the obesity epidemic in which the aim is to reduce oil absorption stand in contrast to the need to increase the poor lipid absorption in an immature digestive system or in patients with cystic fibrosis $(5,6)$. Our knowledge of lipid metabolism has played a part in the development of structured lipids. These lipids are obtained synthetically by changing the fatty acid composition and/or their distribution in the glycerol backbone in order to meet a specific need and improve their nutritional or functional properties (7). Betapol ${ }^{\mathrm{TM}}$ and Salatrim are structured lipids produced with nutritional purposes. One is a substitute for human milk fat and the other one is a reduced-calorie fat. Structured lipids may also mimic desirable physicochemical properties. Plastic fats and cocoa butter equivalents prepared from lower value fats and oils can also be synthesized $(8,9)$.

There are technological and biological methods of modifying oils and fats that may expand their uses. The biological methods include genetic engineering and crop or animal control (4). The technological methods include blending and fractionation, which are physical processes that produce value-added fats and oils (1). However, it is not always easy to predict what will happen to minor components that could affect the oxidative stability of products (4). Hydrogenation solved this problem, allowing for the production of fats with creaming properties, frying stability, sharp melting properties, or other functional characteristics for specific applications while enhancing oxidative stability (1). However, hydrogenated fats contain the two least desirable fatty acids: saturated and trans $(10,11)$. Full hydrogenation is an alternative that produces hard fats, which may be used to prepare low to zero-trans commercial fats through interesterification (12, 13). An interesting raw material that can be used in this process is fully hydrogenated soybean oil. This is a relatively low-cost product with a high C18:0 content (around $85 \%$ ). It is not atherogenic and has none of the adverse effects on cardiovascular diseases reported for shorter fatty acids (C12:0, C14:0 and C16:0) (13).

Interesterification is a reaction through which it is possible to rearrange the fatty acids in the triacylglycerol molecule so that its composition changes but the fatty acid profile is preserved (14-16). There are two ways to carry out interesterification: chemical and enzymatic. Chemical interesterification requires an alkaline catalyst. It is relatively inexpensive, readily available, and easy to use and scale-up. However, it lacks specificity, offering little or no control over the position in which fatty acids are distributed in the final product $(7,17)$. Enzymes can be used to increase the amount of control that one can have over the nature of the product as a consequence of the specificity shown by many lipases. As such, enzymatical- ly interesterified lipids have a more defined structure $(11,18)$. The enzymatic process offers milder reaction conditions and thus lowers degradation of long-chain polyunsaturated fatty acids. Moreover, it also produces fewer by-products than the chemical process (19-21). In this respect, raw materials such as walnut oil are of great interest. Walnuts are unique within the nut family due to their high polyunsaturated fatty acid content, specifically $\mathrm{C} 18: 3 \mathrm{n} 3$, and a ratio of $\mathrm{C} 18: 2 \mathrm{n} 6 / \mathrm{C} 18: 3 \mathrm{n} 3$ of $4: 1$, which has shown to decrease the risk of heart disease (22).

In accordance, the aim of this study is to compare chemical and enzymatic interesterification of binary blends of fully hydrogenated soybean oil and walnut oil and evaluate them in the synthesis of a zero trans-fat and high C18:3n3 fat bases.

\section{Materials and Methods}

\section{Materials}

Raw materials for chemical and enzymatic interesterification were fully hydrogenated soybean oil supplied by Watt's S.A. (Santiago, Chile) and walnuts donated by Valbifrut S.A. (Santiago, Chile). Walnut oil was obtained by cold pressing. The product was also neutralized and bleached (23). Fully hydrogenated soybean oil and walnut oil were stored at $4{ }^{\circ} \mathrm{C}$ in a nitrogen atmosphere until the experiments were conducted. Raw materials were chosen because of the saturated fatty acid content of fully hydrogenated soybean oil and the associated high melting point $\left(68-75^{\circ} \mathrm{C}\right)$, and the high $\mathrm{C} 18: 3 \mathrm{n} 3$ content of walnut oil (14\%), as shown in Table 1 . For chemical interesterification, analytical grade sodium methoxide $(95 \%$, Sigal Ltda., Santiago, Chile) and citric acid monohydrate

Table 1. Fatty acid composition of raw materials: fully hydrogenated soybean oil (FHSBO), walnut oil and FHSBO/walnut oil mixes

\begin{tabular}{lcccrr}
\hline & \multicolumn{5}{c}{$w / \%$} \\
\cline { 2 - 6 } Fatty acid & \multirow{2}{*}{ FHSBO } & Walnut & \multicolumn{3}{c}{ FHSBO/walnut oil } \\
\cline { 4 - 6 } & & & $20: 80$ & $40: 60$ & $60: 40$ \\
\hline not determined & 0.38 & 0.59 & 0.51 & 0.46 & 0.42 \\
C12:0 & 0.98 & - & 0.39 & 0.59 & 0.78 \\
C14:0 & 0.44 & 0.03 & 0.19 & 0.28 & 0.36 \\
C15:0 & 0.05 & - & 0.02 & 0.03 & 0.04 \\
C16:0 & 10.06 & 7.65 & 8.61 & 9.10 & 9.58 \\
C16:1/17:0 & 0.20 & 0.16 & 0.18 & 0.18 & 0.19 \\
C18:0 & 87.18 & 2.4 & 36.31 & 53.27 & 70.22 \\
C18:1 isomer & - & 0.31 & 0.19 & 0.12 & 0.06 \\
C18:1n9-trans & 0.03 & - & 0.01 & 0.02 & 0.02 \\
C18:1n9-cis & 0.17 & 16.36 & 9.88 & 6.65 & 3.41 \\
C18:2 isomer & 0.05 & 1.86 & 1.14 & 0.77 & 0.41 \\
C18:2n6 & 0.06 & 56.52 & 33.94 & 22.64 & 11.35 \\
C18:3 isomer & - & 0.32 & 0.19 & 0.13 & 0.06 \\
C18:3n3 & - & 13.78 & 8.27 & 5.51 & 2.76 \\
C22:0 & 0.37 & 0.02 & 0.16 & 0.23 & 0.30 \\
C24:0 & 0.04 & - & 0.02 & 0.02 & 0.03 \\
\hline
\end{tabular}


(Merck, Santiago, Chile) were used. For enzymatic interesterification, Granotec Chile S.A. (Santiago, Chile) donated Lipozyme ${ }^{\circledast}$ TL IM, an immobilized and sn-1 and sn-3 stereospecific enzyme obtained from Thermomyces lanuginosus.

\section{Chemical interesterification}

Blends of fully hydrogenated soybean oil and walnut oil made at three mass ratios (20:80, 40:60 and 60:40) were chemically interesterified following the procedure described by Rodríguez et al. (24). Briefly, each blend was dried under vacuum conditions $(100 \mathrm{~mm} \mathrm{Hg}$ ) and heated with constant stirring (at $150 \mathrm{rpm}$ ) in a thermoregulated bath until it reached $(90 \pm 2){ }^{\circ} \mathrm{C}$. Next, $0.5 \%$ (by mass) sodium methoxide was added and the reaction was carried out for 10, 15 or $60 \mathrm{~min}$. Citric acid monohydrate was added to stop the reaction (1.78 g per $\mathrm{g}$ of sodium methoxide) and kept for $5 \mathrm{~min}$. The interesterified blend was then washed three times with distilled water to remove the produced soap and any residue of sodium methoxide or citric acid monohydrate.

\section{Enzymatic interesterification}

Blends of fully hydrogeneated soybean oil and walnut oil made at three mass ratios (20:80, 40:60 and 60:40) were enzymatically interesterified following the method reported by Abigor et al. (25). Each blend was dried under vacuum conditions $(100 \mathrm{mmHg})$ and heated with constant stirring (at $150 \mathrm{rpm}$ ) in a thermoregulated bath until it reached $(70 \pm 2){ }^{\circ} \mathrm{C}$, a lower temperature than the one required for chemical interesterification. Next, $5 \%$ (by mass) Lipozyme TL IM was added. The reaction was carried out for 30, 120 or $240 \mathrm{~min}$. In order to stop the reaction, the enzyme was removed by filtration. All of the chemically and enzymatically interesterified blends were stored at 4 ${ }^{\circ} \mathrm{C}$ in a nitrogen atmosphere.

\section{Solid fat content}

Because interesterification modifies the melting profile of lipids, which becomes constant when equilibrium is reached (10), the solid fat content was measured and used as an indicator of this. The solid fat content of interesterified blends was measured using pulsed nuclear magnetic resonance ( $\mathrm{p}-\mathrm{NMR}$ ) according to the AOCS Official Method Cd 16-81 (26). Briefly, dry and filtered samples were placed in glass tubes and completely melted (at $60^{\circ} \mathrm{C}$ and $10 \mathrm{~min}$ ) and then solidified (at $0^{\circ} \mathrm{C}$ and $30 \mathrm{~min}$ ). Samples were then allowed to dissolve in water at 10.0, 21.1, 26.7, 33.3 and $40.0^{\circ} \mathrm{C}$ for $15 \mathrm{~min}$. Finally, the solid fat content was measured at each temperature in a Bruker Minispec PC120s p-NMR analyzer (Bruker Analytische Mestechnik, Rheinstetten, Germany).

\section{Fatty acid profile}

Methylated fatty acids of the triacylglycerols were analyzed in an HP 5890 gas chromatograph (Hewlett-Packard, Palo Alto, CA, USA). A fused silica capillary column BPX70 (0.25 $\mu \mathrm{m}$ film thickness, $50 \mathrm{~m}$ length, 0.33 mm i.d.; SGE Analytical Science, Austin, TX, USA) was used. Samples were run with hydrogen as the carrier gas between 160 and $230{ }^{\circ} \mathrm{C}$ at a rate of $2{ }^{\circ} \mathrm{C} / \mathrm{min}$. Standard fatty acid methyl esters from Merck (Darmstadt, Germany) were used for identification purposes.

\section{Statistical analysis}

All of the analyses were carried out in triplicate and the results are expressed as mean values \pm standard error of the mean (SEM). Statistical differences between the times and mass ratios were determined using one-way analysis of variance and Fisher's test. Differences were considered significant at $p<0.05$. Statistical analysis was performed using Statgraphics v. 4.0 (StatPoint, Inc., Warrenton, VA, USA).

\section{Results and Discussion}

Chemical and enzymatic interesterification were carried out to obtain a fat base with a high content of $\mathrm{C} 18: 3 \mathrm{n} 3$ and zero trans-fats, as shown in Table 1.

\section{Chemically interesterified fat}

Fig. 1 shows the solid fat content of blends of fully hydrogenated soybean oil and walnut oil with mass ratios of 20:80, 40:60 and 60:40 interesterified for 0 (non-interesterified), 10, 15 and $60 \mathrm{~min}$. As we expected, the blends with higher fully hydrogenated soybean oil content had the highest solid fat content. Fully hydrogenated soybean oil is composed exclusively of saturated fatty acids and may contain traces of unsaturated fatty acids (Table 1). As the content of walnut oil in the blend increased, the solid fat content decreased due to the high content of unsaturated fatty acids. The chemical interesterification had the same effect on all blends: the reaction reduced the solid fat content at all temperatures. Our results echo those reported in other studies $(15,24,27)$, of reduced melting point after interesterification; however, the contrary effect - an increase of the solid fat content produced by interesterification - may also happen $(14,28)$. The chosen conditions, temperature and catalyst concentration, allowed thermodynamic equilibrium to be reached after a few minutes. This effect was reflected in the stabilization of melting temperature. No significant differences in solid fat content in the 20:80 blend were found with subsequent measurements after $10 \mathrm{~min}$ and in blends 40:60 and 60:40 after $15 \mathrm{~min}$. Furthermore, the beginning of the reaction was retarded with increasing content of walnut oil. While the 20:80 blend had interesterified in $10 \mathrm{~min}$, the melting point of the $40: 60$ blend after $10 \mathrm{~min}$ of interesterification was found at significantly lower temperatures than at the beginning of the reaction, although it was still not stabilized. Interestingly, this particular blend (Fig. 1b) shows evident variability after $10 \mathrm{~min}$ (high standard error of the mean), probably denoting a transition state, which reflects how unstable the solid fat content of a blend may be during the interesterification. It can also be noticed that after $10 \mathrm{~min}$ of interesterification, the melting point of the $60: 40$ blend did not change significantly from that observed in the non-interesterified blend. These results suggest that the beginning of the reaction is delayed with an increase in the content of fully hydrogenated soybean oil. Comparing our results to those reported, the reaction time may not be relevant because it might vary widely ( 5 

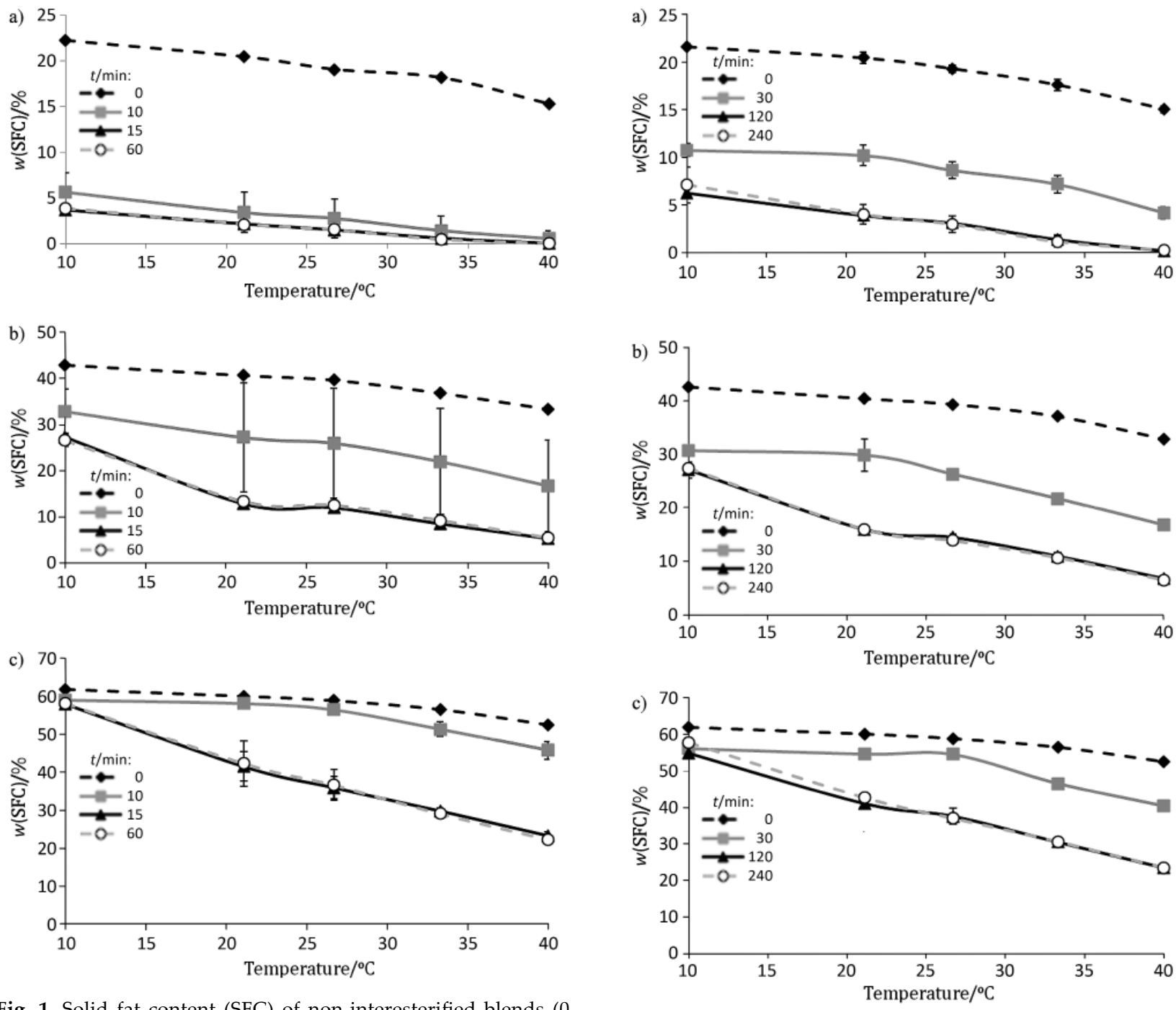

Fig. 1. Solid fat content (SFC) of non-interesterified blends $(0$ $\mathrm{min}$ ) and chemically interesterified blends of fully hydrogenated soybean oil and walnut oil at mass ratios of: a) 20:80, b) 40:60 and c) 60:40, measured for 10, 15 and $60 \mathrm{~min}$ at different temperatures

min to $6 \mathrm{~h}$, or even longer) depending on the conditions such as the catalyst concentration, temperature and solubility of catalysts in the reactants (15). In general, the reaction is accelerated with the increase in catalyst concentration and temperature, but the effect of solubility of the catalyst depends on the raw materials, mass ratios and the catalyst itself.

\section{Enzymatically interesterified fat}

Fig. 2 shows the melting profiles of fully hydrogenated soybean oil and walnut oil blends at mass ratios of 20:80, 40:60 and 60:40 interesterified for 0 (non-interesterified), 30, 120 and $240 \mathrm{~min}$. As we observed with chemical interesterification, blends with higher content of fully hydrogenated soybean oil present higher melting temperatures, which are reduced with the addition of walnut oil. Also, the solid fat content of all blends decreases as the reaction progresses. Díaz Gamboa and Gioelli (29) synthesized functional triacylglycerols using chemical and enzymatic interesterification. They reported that the

Fig. 2. Solid fat content (SFC) of non-interesterified blends (0 $\mathrm{min}$ ) and enzymatically interesterified blends of fully hydrogenated soybean oil and walnut oil at mass ratios of: a) 20:80, b) 40:60 and c) 60:40, measured for 30, 120 and 240 min at different temperatures

addition of a solid fat to liquid oil increases the solid fat content of the blend, which decreases after interesterification, as we found in our experiments. They also reported solid fat content at lower temperatures after interesterification of pure palm kernel fat. The thermodynamic equilibrium of all the fully hydrogenated soybean oil and walnut oil blends was achieved at $120 \mathrm{~min}$ when the solid fat content was stabilized. This coincides with the results of the study by Undurraga et al. (8), who reported total interesterification after 80-120 min under similar conditions $\left(65^{\circ} \mathrm{C}\right.$, Lipozyme TL IM). However, as in chemical interesterification, the temperature and the catalyst concentration affected the rate of the enzymatic reaction. Interesterification speeds up when temperature increases until it reaches a maximum level. At that point, it starts to slow down as the temperature increases due to the loss of enzyme activity (30). The catalyst concentration generally has the same effect. As the enzyme load increases, the reaction rate is accelerated, but above a certain amount, there is no effect (31). 


\section{Interesterified blends as a fat base for margarine}

In order to obtain an interesterified fat similar to a fat base for margarine, the melting profiles of a commercial fat base and interesterified blends were compared. Fig. 3 shows the melting profiles of the interesterified mixtures and the commercial base. Although differences between the curves of the commercial base and the studied mixtures are observed, the 40 :60 blend shows physical behaviour similar to that of the commercial base. Chemically and enzymatically interesterified blends exhibited a spreadability as good as a commercial fat with $27 \%$ of solid fat at $10^{\circ} \mathrm{C}$; a solid fat content not greater than $32 \%$ is essential for good spreadability at refrigeration temperature. Interesterified blends also showed good stability and resistance to oil exudation at room temperature with a solid fat content over $10 \%$ at $21.1{ }^{\circ} \mathrm{C}(13$ and $16 \%$ in chemically and enzymatically interesterified blends, respectively). The poorest behaviour of interesterified blends was at body temperature. Under these conditions, the contents of 9 and $11 \%$ of solids at $33^{\circ} \mathrm{C}$ for chemically and enzymatically obtained products produced a waxier sensation in the mouth. Ideally, the solid fat content should be less than $3.5 \%$ at $33.3{ }^{\circ} \mathrm{C}(32-34)$. However, the solid fat content of both interesterified blends had plasticity curves that fall within the range of all-purpose-type shortening fats. According to List et al. (35), the solid fat content required at $10,21.1,26.6,33.3$ and $40{ }^{\circ} \mathrm{C}$ is $18-23$, $14-19,13-14,12-13$ and $7-11 \%$, respectively. Overall, the interesterified blends achieved these requirements. However, at $10{ }^{\circ} \mathrm{C}$, the solid fat content was slightly higher than that of shortening fats.

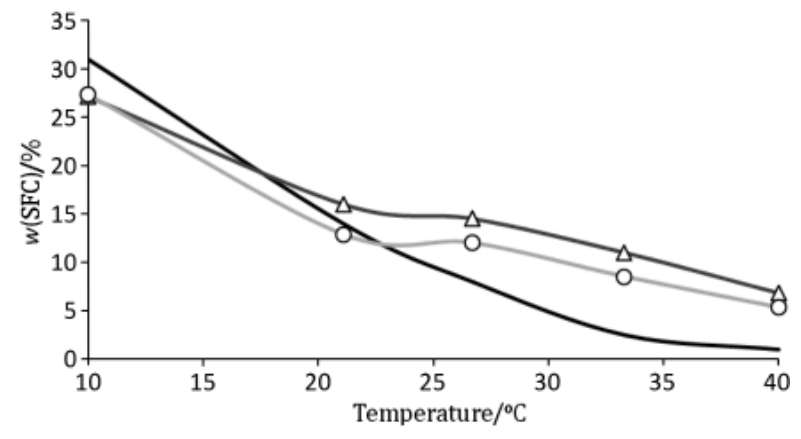

Fig. 3. Solid fat content (SFC) of chemically (-O-) and enzymatically interesterified $(\triangle)$ blends of fully hydrogenated soybean oil and walnut oil at mass ratio of 40:60, and of a commercial fat base (-), measured at different temperatures

There are no physical differences between the chemically and enzymatically interesterified blends. Other differences between chemically and enzymatically interesterified fats may be produced by the process itself. The main advantage of the enzymatic process over the chemical one is that the latter produces complete randomization of fatty acids, while enzymatic interesterification may be either substrate specific, differentiated by chain length, or stereospecific. The stereospecificity of commercial enzymes allows them to produce structured lipids with mainly nutritional advantages. Essential fatty acids are usually bonded at the sn-2 position of triacylglycerol; if these oils are enzymatically interesterified, the essential fatty acids remain at the sn-2 position, where they are more easily absorbed as sn-2 monoacylglycerol than free fatty acids (36). This improved absorption characteristic is not maximized in chemical interesterification. Enzymatic interesterification is mainly used when a very specific structure is required, as in Betapol ${ }^{\circledast}$, the natural standard for mimicking human milk.

\section{Conclusions}

This study evaluated the suitability of chemical and enzymatic interesterification to produce a fat base rich in polyunsaturated fatty acids. Specifically, fully hydrogenated soybean oil and walnut oil were shown to be adequate raw materials to produce a fat base with good physical and nutritional characteristics, with a high concentration of linolenic acid (C18:3n3), and with zero trans-fat. In addition, fully hydrogenated soybean oil may have additional advantages compared to other solid fats, due to the high concentration of palmitic acid (C18:0), which does not have as many detrimental effects as shorter saturated fatty acids. Overall, both chemically and enzymatically interesterified blends of fully hydrogenated soybean oil and walnut oil at 40:60 mass ratio resulted in the plasticity of the shortening fat and no significant differences were found between both technologies. Additional studies related to the fatty acid bioavailability of the different mixes could be done in the future to determine if there could be any drawbacks in terms of fatty acid availability when comparing a blend with its interesterified mix. This analysis could also be reinforced through the study of the molecular distribution of the different fatty acids along the glycerol backbone after interesterification.

\section{Acknowledgements}

The authors wish to express their appreciation for the support from Pontificia Universidad Católica de Chile and Project Anillo ACT1105/2012 Healthy Food Matrix Design.

\section{References}

1. O'Brien R. Fats and oils: formulating and processing for applications. Boca Raton, FL, USA: CRC Press; 2004.

2. Babayan VK. Medium chain triglycerides and structured lipids. Lipids. 1987;22:417-20. http://dx.doi.org/10.1007/BF02537271

3. Garaiova I, Guschina IA, Plummer SF, Tang J, Wang D, Plummer NT. A randomised cross-over trial in healthy adults indicating improved absorption of omega-3 fatty acids by pre-emulsification. Nutr J. 2007;6:4. http://dx.doi.org/10.1186/1475-2891-6-4

4. Gunstone FD. Modifying lipids - why and how? In: Gunstone FD, editor. Modifying lipids for use in food. Boca Raton, FL, USA: CRC Press LLC; 2006. pp. 1-8.

5. López-López A, Castellote-Bargalló A, Campoy-Folgoso C, Rivero-Urgel M, Tormo-Carnicé R, Infante-Pina D, LópezSabater MC. The influence of dietary palmitic acid triacylglyceride position on the fatty acid, calcium and magnesium contents of at term newborn faeces. Early Hum Dev. 2001; 65:S83-94.

http://dx.doi.org/10.1016/S0378-3782(01)00222-5 
6. Innis SM, Dyer R, Quinlan P, Diersen-Schade D. Palmitic acid is absorbed as sn-2 monopalmitin from milk and formula with rearranged triacylglycerols and results in increased plasma triglyceride sn- 2 and cholesteryl ester palmitate in piglets. J Nutr. 1995;125:73-81.

http://dx.doi.org/10.3945/an.111.000448

7. Osborn HT, Akoh CC. Structured lipids - novel fats with medical, nutraceutical, and food applications. Compr Rev Food Sci. 2002;1:110-20. http://dx.doi.org/10.1111/j.1541-4337.2002.tb00010.x

8. Undurraga D, Markovits A, Erazo S. Cocoa butter equivalent through enzymatic interesterification of palm oil midfraction. Process Biochem. 2001;36:933-9.

http://dx.doi.org/10.1016/S0032-9592(00)00260-0

9. Berger KC, Idris NA. Formulation of zero-trans acid shortenings and margarines and other food fats with products of the oil palm. J Am Oil Chem Soc. 2005;82:755-82. http://dx.doi.org/10.1007/s11746-005-1143-9

10. Idris NA, Mat-Dian LH. Interesterified palm products as alternatives to hydrogenation. Asia Pac J Clin Nutr. 2005;14: 396-401.

11. List GR, King JW. Hydrogenation of lipids for use in food. In: Gunstone FD, editor. Modifying lipids for use in food. Boca Raton, FL, USA: CRC Press LLC; 2006. pp. 173-200.

12. Petrauskaite V, De Greyt W, Kellens M, Huyghebaert A. Physical and chemical properties of trans-free fats produced by chemical interesterification of vegetable oil blends. J Am Oil Chem Soc. 1998;75:489-93. http://dx.doi.org/10.1007/s11746-998-0252-z

13. Ribeiro APB, Grimaldi R, Gioelli LA, Gonçalves LAG. Zero trans fats from soybean oil and fully hydrogenated soybean oil: physico-chemical properties and food applications. Food Res Int. 2009;42:401-10.

http://dx.doi.org/10.1016/j.foodres.2009.01.012

14. Rodrigues JN, Gioielli LA. Chemical interesterification of milkfat and milkfat-corn oil blends. Food Res Int. 2003;36: 149-59. http://dx.doi.org/10.1016/S0963-9969(02)00130-8

15. Klinkesorn U, H-Kittikun A, Chinachoti P, Sophanodora P. Chemical transesterification of tuna oil to enriched omega-3 polyunsaturated fatty acids. Food Chem. 2004;87:415-42. http://dx.doi.org/10.1016/j.foodchem.2003.12.021

16. Liu WH, Inbaraj BS, Chen BH. Analysis and formation of trans fatty acids in hydrogenated soybean oil during heating. Food Chem. 2007;104:1740-9. http://dx.doi.org/10.1016/j.foodchem.2006.10.069

17. Mangos TJ, Jones KC, Foglia TA. Lipase-catalyzed synthesis of structured low-calorie triacylglycerols. J Am Oil Chem Soc. 1999;76:1127-32. http://dx.doi.org/10.1007/s11746-999-0084-5

18. Hamam F, Daun J, Shahidi F. Lipase-assisted acidolysis of high-laurate canola oil with eicosapentaenoic acid. J Am Oil Chem Soc. 2005;82:875-9. http://dx.doi.org/10.1007/s11746-005-1158-2

19. Fomuso LB, Akoh CC. Enzymatic modification of triolein: incorporation of caproic and butyric acids to produce reduced-calorie structured lipids. J Am Oil Chem Soc. 1997;74: 269-72. http://dx.doi.org/10.1007/s11746-997-0134-9

20. Osório NM, Ferreira-Dias S, Gusmão JH, da Fonseca MMR. Response surface modelling of the production on $\omega-3$ polyunsaturated fatty acids-enriched fats by a commercial immobilized lipase. J Mol Catal B-Enzym. 2001;11:677-86. http://dx.doi.org/10.1016/S1381-1177(00)00156-9

21. Rønne TH, Pedersen S, Xu X. Triglyceride selectivity on immobilized Thermomyces lanuginosa lipase in interesterifica- tion. J Am Oil Chem Soc. 2005;82:737-43.

http://dx.doi.org/10.1007/s11746-005-1136-8

22. Davis L, Stonehouse W, Loots DT, Mukuddem-Petersen J, Van der Westhuizen FH. The effects of high walnut and cashew nut diets on the antioxidant status of subjects with metabolic syndrome. Eur J Nutr. 2007;46:155-64. http://dx.doi.org/10.1007/s00394-007-0647-x

23. Bailey AE. Industrial oils and fats. Barcelona, Spain: Editorial Reverté; 1961 (in Spanish).

24. Rodríguez A, Castro E, Salinas MC, López R, Miranda M. Interesterification of tallow and sunflower oil. J Am Oil Chem Soc. 2001;78:431-6. http://dx.doi.org/10.1007/s11746-001-0280-5

25. Abigor R, Marmer W, Foglia T, Jones K, DiCiccio R, Ashby R, Uadia P. Production of cocoa butter-like fats by lipase-catalized interesterification of palm oil and hydrogenated soybean oil. J Am Oil Chem Soc. 2003;80:1193-6. http://dx.doi.org/10.1007/s11746-003-0841-7

26. AOCS Official Method Cd 16-81. Solid fat content (SFC) by low-resolution nuclear magnetic resonance? The indirect method. In: Official Methods and Recommended Practices of the American Oil Chemists' Society; Champaign, IL, USA: AOCS; 1993.

27. Norizzah AR, Chong CL, Cheow CS, Zaliha O. Effects of chemical interesterification on physicochemical properties of palm stearin and palm kernel olein blends. Food Chem. 2004;86:229-35.

http://dx.doi.org/10.1016/j.foodchem.2012.09.086

28. Kellens M. Developments in the technology for modification of fats. In: 10th Anniversary of Argentinian Association of Fats and Oils. Santa Fe, Argentina: Editorial Amalevi; 2000. pp. 246-61 (in Spanish).

29. Díaz-Gamboa O, Gioielli L. Structured lipids obtained by chemical and enzymatic interesterification from fish oil and palm kernel fat. Grasas Aceites. 2003;54:161-8. http://dx.doi.org/10.3989/gya.2003.v54.i2.259

30. Namal Senananyake SPJ, Shahidi F. Enzyme-catalyzed synthesis of structured lipids via acidolysis of seal (Phoca groenlandica) blubber oil with capric acid. Food Res Int. 2002;35: 745-52. http://dx.doi.org/10.1016/S0963-9969(02)00070-4

31. Wang HX, Wu H, Ho CT, Weng XC. Cocoa butter equivalent from enzymatic interesterification of tea seed oil and fatty acid methyl esters. Food Chem. 2006;97:661-5. http://dx.doi.org/10.1016/j.foodchem.2005.04.029

32. Criado M, Hernández-Martín E, López-Hernández A, Otero C. Enzymatic interesterification of extra virgin olive oil with a fully hydrogenated fat: characterization of the reaction and its products. J Am Oil Chem Soc. 2007;84:717-26. http://dx.doi.org/10.1007/s11746-007-1104-y

33. Karabulut I, Turan S, Ergin G. Effects of chemical interesterification on solid fat content and slip melting point of fat/oil blends. Eur Food Res Technol. 2004;218:224-9. http://dx.doi.org/10.1007/s00217-003-0847-4

34. Seriburi V, Akoh CC. Enzymatic interesterification of lard and high-oleic sunflower oil with Candida antarctica lipase to produce plastic fats. J Am Oil Chem Soc. 1998;75:1339-45. http://dx.doi.org/10.1007/s11746-998-0181-x

35. List GR, Mounts TL, Orthoefer F, Neff WE. Margarine and shortening oils by interesterification of liquid and trisaturated triglycerides. J Am Oil Chem Soc. 1995;72:379-82. http://dx.doi.org/10.1007/BF02541100

36. Willis W, Lencki R, Marangoni A. Lipid modification strategies in the production of nutritionally functional fats and oils. Crit Rev Food Sci. 1998;38:639-74. http://dx.doi.org/10.1080/10408699891274336 